\title{
Pulmonary embolism in a man with an implantable cardioverter defibrillator
}
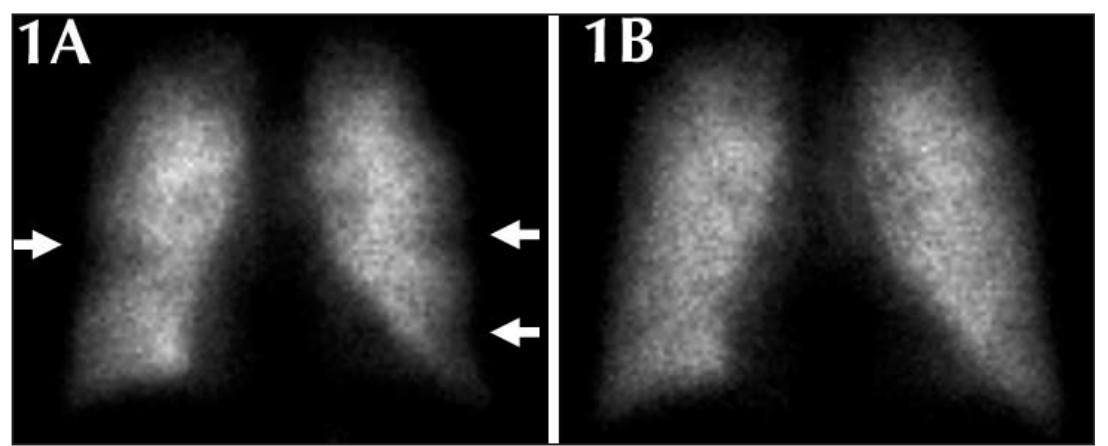

herent to the wall of the chamber and only discharge if the device detects a potentially fatal cardiac arrhythmia. Although thrombi are rarely seen on pacemaker leads, the incidence of thrombi on ICD leads may be much higher. ${ }^{2} \mathrm{~A}$ study in-
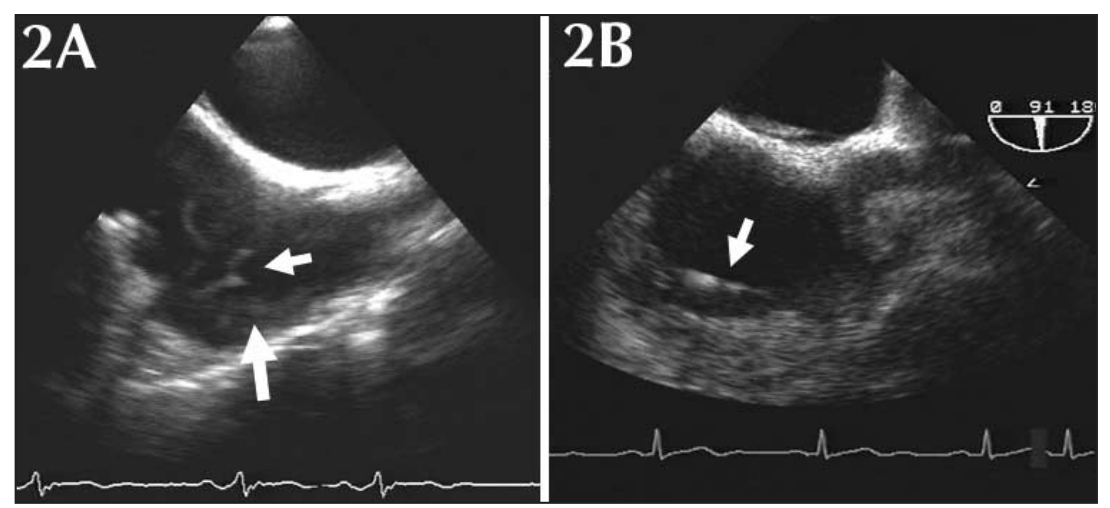
volving 185 patients who underwent ICD implantation showed a $25 \%$ incidence of lead-related thrombi at the 4-month follow-up with transesophageal echocardiography. ${ }^{2}$ Only 1 patient had symptoms of pulmonary embolism. It has been hypothesized that the large caliber of the

462-year-old man was resusAcitated from a ventricular fibrillation cardiac arrest. His coronary angiogram was normal, and a gated blood pool scan demonstrated normal left ventricular function. An implantable cardioverter defibrillator (ICD; Medtronic Microjewel II defibrillator and Medtronic Sprint 6943 ventricular lead) was implanted to protect against arrhythmia recurrence.

One month later acute-onset pleuritic chest pain and dyspnea developed. The ICD had no previous discharges. A ventilation-perfusion scan showed a high probability for recent pulmonary embolism, with subsegmental perfusion defects in the right middle lobe and lingula (Fig. 1A, arrows) with normal ventilation (Fig. 1). Transesophageal echocardiography revealed multiple filamentous thrombi (Fig. 2A, small arrow) on the transvenous ICD lead (Fig. 2A, large arrow) at the right atrium (a video of the echocardiogram is available at www.cmaj.ca/cgi/content/full/173 /5/487/DC1). A thrombophilia workup (factor $\mathrm{V}$ Leiden, prothrombin gene, protein $\mathrm{S}$, protein $\mathrm{C}$, homocysteine and lupus anticoagulant) yielded negative results.

The patient was given anticoagulation therapy with coumadin, and transesophageal echocardiography at 3 months revealed complete resolution of the leadrelated thrombi (Fig. 2B, arrow; a video of the echocardiogram is available at www.cmaj.ca/cgi /content/full/173/5/487/DC1). The patient remained well, and his pulmonary perfusion defects were no longer seen on a followup ventilation-perfusion scan.

ICDs are used for the primary and secondary prevention of arrhythmic death, and their use is on the rise. An ICD pulse generator is implanted subcutaneously, and transvenous endocardial leads are implanted in the right ventricle and sometimes the right atrium. ${ }^{1}$ The leads are ad-
ICD lead compared with the pacemaker lead, the type of insulation material (polyurethane may be prone to thrombus) or frequent ICD discharges may contribute to thrombus formation. It is currently unknown whether pulmonary emboli will develop in patients with asymptomatic lead-related thrombi.

At this point, there is insufficient evidence to recommend routine echocardiography for the detection of thrombi after ICD insertion or prophylactic anticoagulation for all patients with ICDs.

\section{Benjamin Chow \\ Anthony Tang \\ University of Ottawa Heart \\ Institute \\ Ottawa, Ont.}

\section{References}

1. Davis DR, Tang AS. Implantable cardioverter defibrillators: therapy against Canada's leading killer. CMAF 2004; 171(9):1037-8.

2. Chow BJ, Hassan AH, Chan KL, Tang AS. Prevalence and significance of lead-related thrombi in patients with implantable cardioverter defibrillators. Am 7 Cardiol 2003;91(1):8. 